\title{
Efficacy and Tolerability of Low-Dose Perampanel in Patients with Childhood-Onset Intractable Epilepsy
}

\author{
Hyeonmin Park, MD, Hyunji Ahn, MD, Han Na Jang, MD, Hyun-Jin Kim, MD, Mi-Sun Yum, MD, \\ Tae-Sung Ko, MD
}

Department of Pediatrics, Asan Medical Center Children's Hospital, University of Ulsan College of Medicine, Seoul, Korea

Received: August 21, 2019

Revised: September 23, 2019

Accepted: September 23, 2019

Corresponding author:

Tae-Sung Ko, MD

Department of Pediatrics, Asan

Medical Center Children's Hospital,

University of Ulsan College of

Medicine, 88 Olympic-ro 43-gil,

Songpa-gu, Seoul 05505, Korea

Tel: +82-2-3010-3386

Fax: +82-2-473-3725

E-mail: tsko@amc.seoul.kr
Purpose: The aim of this study was to evaluate the efficacy and tolerability of perampanel as adjunctive therapy in childhood-onset refractory epilepsy.

Methods: We retrospectively reviewed the medical records of 110 patients who were treated with perampanel in Asan Medical Center children's hospital. Two patients with poor compliance were excluded and 108 patients were enrolled. The clinical characteristics were reviewed, and the total seizure frequency before and after the add-on of perampanel was analyzed.

Results: The mean age of the patients (64 males) was 20.2 years (range, 10.5 to 35.6). The mean maintenance dose was $4.8 \mathrm{mg} /$ day (2 to $10 \mathrm{mg}$ ). Eight patients (7.4\%) achieved seizure freedom and $35(32.4 \%)$ achieved a seizure reduction of $\geq 50 \%$. Among them, three patients achieved seizure freedom with only $2 \mathrm{mg} /$ day of perampanel. There was no significant difference in sex, age at seizure onset, duration of epilepsy, use of concomitant enzyme-inducing antiepileptic drugs, number of concomitant antiepileptic drugs, and adverse events between responders and non-responders. The retention rate was up to $68.0 \%$ in the first year and 59.5\% in the second year of the study. Thirty-four patients (31.5\%) reported adverse events: violence, somnolence, dizziness, drooling, weight gain, insomnia, and vomiting. There was no contributing factor for the adverse events, including sex, age, and the number of concomitant antiepileptic drugs and enzyme-inducing antiepileptic drugs when comparing the adverse event present group with the adverse event absent group.

Conclusion: Low-dose perampanel showed reasonable efficacy and tolerability in patients with refractory childhood-onset epilepsy. Further validation with pharmacokinetic studies is needed.

Keywords: Perampanel; Drug resistant epilepsy; Drug-related side effects and adverse reactions; Treatment outcome

\section{Introduction}

Childhood-onset epilepsy is a common neurological disease that affects approximately 0.5 to 1 in every 100 children and young people [1]. Despite the many newly developed antiepileptic drugs (AEDs), $20 \%$ to $30 \%$ of patients do not achieve acceptable seizure control with the current pharmacotherapy. Drug-resistant seizures can cause cognitive impairment, behavioral and mental health problems, and eventual deterioration of their quality of life [2]. Thus, early seizure control with appropriate AEDs is very important for patients with epilepsy.

Perampanel (PER) is a highly selective, non-competitive, orally

Copyright(C) 2019 Korean Child Neurology Society

This is an Open Access article distributed under the terms of the Creative Commons Attribution Non-Commercial License (http://creativecommons.org/licenses/by-nc/4.0/) which permits unrestricted non-commercial use, distribution, and reproduction in any medium, provided the original work is properly cited. 
active antagonist of the $\alpha$-amino-3-hydroxy-5-methyl-4-isoxazolepropionic acid (AMPA) receptors for glutamate, the major excitatory neurotransmitter in the central nervous system [3-5]. The role of AMPA receptors in the generation and spread of epileptic seizures has been demonstrated in many studies [6-10]. Overexpression of AMPA receptors is also observed in the hippocampal and neocortical tissue of patients with epilepsy [11,12]. PER is mainly metabolized in the liver by cytochrome P450 (CYP3A4/6); therefore, enzyme-inducing antiepileptic drugs (EIAEDs), such as carbamazepine (CBZ), oxcarbazepine (OXC), and phenytoin (PHT), can reduce its concentrations up to $50 \%$ to $60 \%$ [13] and concomitant use of EIAEDs has been reported as a clinical factor for poor response to PER and concomitant use of EIAEDs has been reported as a clinical factor for poor response to PER [14].

PER was initially approved for adjunctive treatment of focal seizures (with or without secondarily generalized seizures) in patients with epilepsy aged $\geq 12$ years [15]. Lately, the U.S. Food and Drug Administration expanded its indication to monotherapy for focal seizures and pediatric patients $\geq 4$ years $[16,17]$. Several prospective and retrospective studies have examined the efficacy and tolerability of PER as an adjunctive AED for epilepsy. They reported that PER can reduce the seizure frequency by at least 50\% in 34\% to $57 \%$ of patients with intractable epilepsy [2,18-26].

In this study, we aimed to examine the tolerability and efficacy of PER as adjunctive therapy in patients with childhood onset epilepsy. In addition, we attempted to determine the possible factors associated with the response rate and adverse events.

\section{Materials and Methods}

We retrospectively reviewed the medical records of 110 patients who were treated with PER as adjunctive therapy in the Asan Medical Center Children's Hospital between May 2016 and May 2018.

We included patients with drug-resistant epilepsy, which was defined as having uncontrolled seizures even with two or more appropriate AEDs. Two patients with poor compliance were excluded and 108 patients were enrolled. This retrospective study was exempt from informed consent per our institutional policies and approved by the Institutional Review Board of Asan Medical Center (2019-1058).

The baseline characteristics, including age, gender, seizure onset, and concomitant AEDs were documented from the electronic medical records. We evaluated the efficacy of PER by comparing the total seizure frequency during 3 months before and after the add-on of PER. The seizure frequency was divided into five categories: seizure-free, seizure reduction $\geq 50 \%$, seizure reduction $<50 \%$, no change, and aggravated. Patients who achieved seizure freedom and seizure frequency reduction $\geq 50 \%$ were assigned into the responder group, and the others were assigned into the non-responder group.

The clinical profiles of the patients in both groups were compared, including the age, gender, daily PER dose, number of concomitant AEDs, and the concomitant use of EIAEDs. The dose-related efficacy was also evaluated.

Tolerability was accessed through review of the medical records for the occurrence of adverse events after the addition of PER, as well as by retention rate measurement. According to the presence of adverse events, the patients were divided into two groups: adverse event present group and adverse event absent group. The clinical profiles of the patients in both groups were compared, including the age, gender, daily PER dose, and the number of concomitant AEDs. The retention rate was calculated using the Kaplan-Meier analysis. Statistical analysis was performed using Pearson's chi-square test and Fisher's exact test for categorical variables. SPSS software version 21.0 (IBM Co., Armonk, NY, USA) was used for descriptive and statistical analysis. A probability value of $P<0.05$ was considered statistically significant.

\section{Results}

\section{Demographic and baseline characteristics of patients}

A total of 108 patients were included in the analysis. The median follow-up duration after the start of PER was 15 months (range, 3 to 24 ). The mean age was 20.2 years (range, 10.5 to 35.6 ) and 64 patients were male. The mean age at the time of the first seizure attack was $8.0 \pm 5.8$ years (range, 0.0 to 29.2). The mean number of concomitant AEDs was $3.8 \pm 1.0$ (range, 2 to 7 ) (Table 1 ). The mean maintenance dose was $4.8 \mathrm{mg} /$ day ( 2 to $10 \mathrm{mg}$ ). PER was initiated at a dose of $2 \mathrm{mg}$ once daily at bedtime and the dose was gradually increased in increments of $2 \mathrm{mg}$ at intervals of at least 1 week, while monitoring the seizure frequency and adverse events occurrence. The most commonly used AEDs with PER were clobazam $(73.6 \%)$, topiramate $(54.5 \%)$, levetiracetam $(51.8 \%)$, valproate (38.2\%), and lamotrigine (38.2\%). The number of patients who were taking EIAEDs (OXC, CBZ, or PHT) were 33 (30\%), 15 (13.6\%), and two (1.8\%), respectively.

\section{Efficacy}

Among the 108 patients, 43 were classified as responders (43/108, $39.8 \%)$, including eight (7.4\%) who achieved seizure freedom and 35 (32.4\%) who achieved $\geq 50 \%$ seizure reduction. Sixty-five patients $(60.2 \%)$ were classified as non-responders; 17 (15.7\%) with less than 50\% seizure reduction, 34 (31.5\%) with no change, and 14 (13\%) with seizure aggravation after the addition of PER (Fig. 1). 
Table 1. Demographics and baseline characteristics of the patients $(n=108)$

\begin{tabular}{lc}
\hline Variable & Value \\
\hline Gender & \\
Male & $64(59.3)$ \\
Female & $44(40.7)$ \\
Age at seizure onset (yr) & $8.0 \pm 5.8(0.0-29.2)$ \\
Age at the start of PER (yr) & $20.2 \pm 5.0(10.5-35.6)$ \\
Duration of seizures before treatment (yr) & $12.1 \pm 5.5(1.2-21.0)$ \\
Mean maintenance dose (mg) & $4.8 \pm 2.3(2-10)$ \\
AEDs at baseline & $3.8 \pm 1.0(2-7)$ \\
2 & $10(9.1)$ \\
3 & $30(27.3)$ \\
4 & $43(39.1)$ \\
5 & $19(17.3)$ \\
6 & $5(4.5)$ \\
7 & $1(0.9)$ \\
\hline
\end{tabular}

Values are presented as number (\%) or mean \pm standard deviation (range). $P E R$, perampanel; AED, antiepileptic drug.

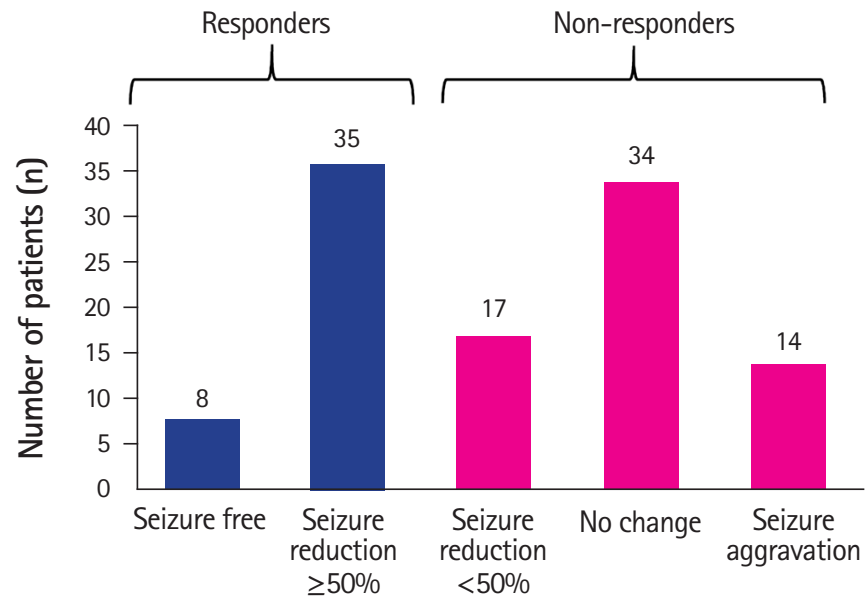

Fig. 1. Number of patients in each group according to the seizure outcome after addition of perampanel. A total of 43 patients achieved seizure freedom or $\geq 50 \%$ seizure reduction and were classified as responders. The remaining 65 patients (60.2\%) were non-responders, consisting of 17 patients (15.7\%) with less than $50 \%$ seizure reduction, $34(31.5 \%)$ with no change, and $14(13 \%)$ with seizure aggravation.

Table 2. Comparison of clinical factors between responder and non-responder group

\begin{tabular}{lccc}
\hline Variable & Responders $(\mathrm{n}=43,39.8 \%)$ & Non-responders $(\mathrm{n}=65,60.2 \%)$ & $P$ value \\
\hline Male sex & $27(61.4)$ & $37(56.9)$ & 0.64 \\
Age at seizure onset (yr) & $9.1 \pm 6.5$ & $7.3 \pm 5.2$ & 0.12 \\
Age at the start of PER (yr) & $21.0 \pm 5.3$ & $19.8 \pm 5.0$ & 0.22 \\
Duration of seizures before treatment (yr) & $11.9 \pm 5.6$ & $12.4 \pm 5.4$ & 0.61 \\
Duration of PER treatment (mo) & $13.5 \pm 7.7$ & $8.7 \pm 8.1$ & 0.03 \\
No. of concomitant AEDs & $3.8 \pm 1.2$ & $3.8 \pm 1.0$ & 0.78 \\
Any ElAEDs & $20(46.5)$ & $27(41.5)$ & 0.61 \\
$\quad 15(34.1)$ & $18(27.7)$ & 0.43 \\
$\quad$ Cxcarbazepine & $5(11.4)$ & $9(13.8)$ & 0.74 \\
$\quad 1(2.3)$ & $1(1.5)$ & 0.77 \\
Phenytoin & $5.3 \pm 2.4$ & $4.4 \pm 2.2$ & 0.04 \\
Adverse events & $12(27.3)$ & $22(33.8)$ & 0.47 \\
No. of patients of PER discontinuation & $4(11.8)$ & $30(88.2)$ & 0.00 \\
\hline
\end{tabular}

Values are presented as number $(\%)$ or mean \pm standard deviation.

$P E R$, perampanel; AED, antiepileptic drug; EIAED, enzyme-inducing antiepileptic drug.

There was no significant difference in the sex, age at seizure onset, duration of epilepsy, number of concomitant AEDs, and adverse events between the two groups (Table 2). The maintenance dose of PER was slightly higher in the responders than in the non-responders ( 5.3 vs. 4.4 , respectively; $P=0.04$ ). Only nine of 29 patients treated with $2 \mathrm{mg}$ of PER were responders. There were 46 patients who could tolerate PER at a higher dose (6 to $10 \mathrm{mg}$ ). Among them, 23 patients ( $50 \%$ ) achieved $\geq 50 \%$ seizure reduction. The response rate at each dose of PER was $0 \%(0 / 1)$ at $1 \mathrm{mg}$; $31.0 \%(9 / 29)$ at $2 \mathrm{mg} ; 33.3 \%(10 / 30)$ at $4 \mathrm{mg} ; 50 \%(1 / 2)$ at 5 $\mathrm{mg} ; 44 \%(11 / 25)$ at $6 \mathrm{mg} ; 100 \%(2 / 2)$ at $7 \mathrm{mg} ; 46.7 \%(7 / 15)$ at $8 \mathrm{mg}$; and $75 \%$ (3/4) at a dose of $10 \mathrm{mg}$ (Fig. $2 \mathrm{~A}$ ).

Duration of PER treatment was much longer in the responders than in the non-responders 13.5 months vs. 8.7 months, respectively; $P=0.03$ ). The number of patients who eventually stopped PER was higher in the non-responders than in the responders (30 vs. 4, respectively; $P<0.001$ ). Patients taking EIAEDs showed a similar response rate when comparing the overall efficacy (CBZ 15/33, 44\%; OXC 6/15, 40\%; PHT 1/2 50\%).

Five of 10 patients (50.0\%) who were started on PER as the 


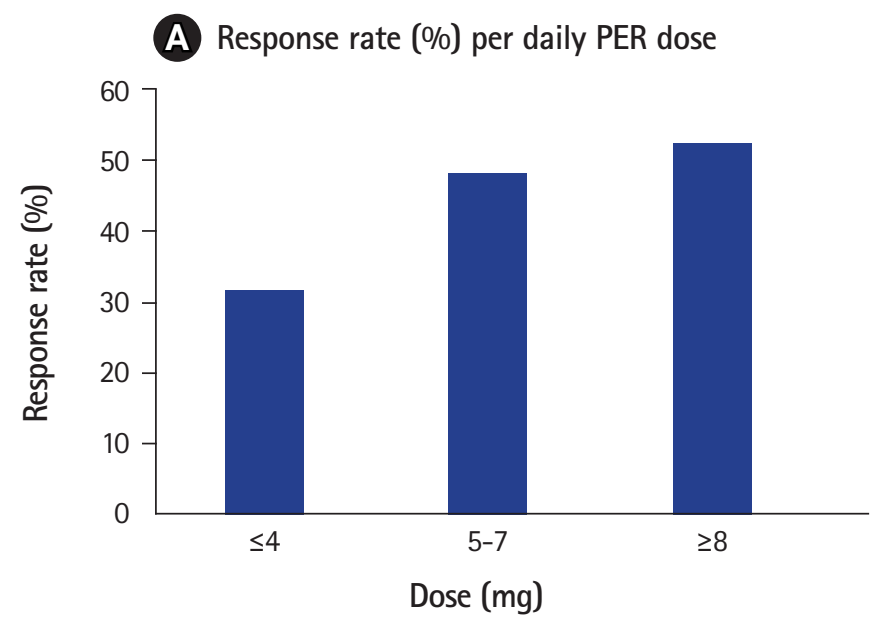

B Adverse events per daily PER dose

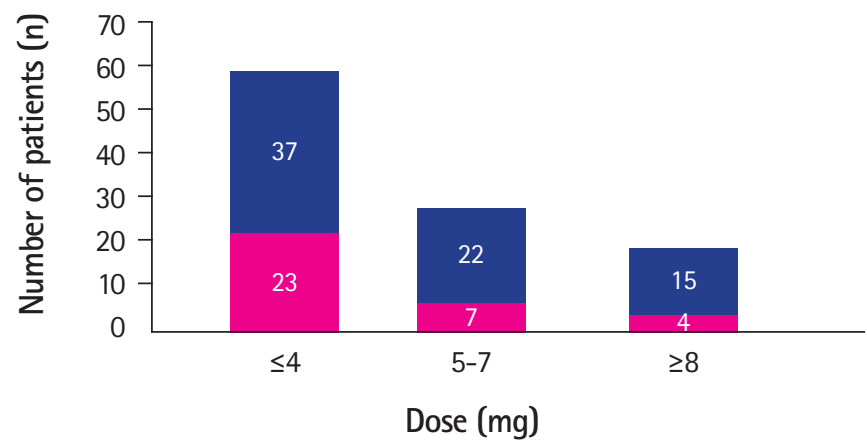

Adverse event present group

Adverse event absent group

Fig. 2. Seizure outcomes and occurrence of adverse events per daily doses of perampanel (PER). (A) The response rates according to daily PER dose are shown as bar graph. Response rate at dose of $\leq 4 \mathrm{mg}$ was $31.7 \%$ while response rate at dose of 5 to $7 \mathrm{mg}$ was $48.7 \%$ and $52.6 \%$ at dose of $\geq 8 \mathrm{mg}$. Patients who could tolerate PER up to a higher dose had a tendency to relatively better seizure outcomes than that of patients who received lower-dose PER. The response rates at each dose are listed (0\% [0/1] at $1 \mathrm{mg} ; 31.0 \%$ [9/29] at $2 \mathrm{mg} ; 33.3 \%$ [10/30] at $4 \mathrm{mg} ; 50 \%$ [1/2] at $5 \mathrm{mg} ; 44 \%$ [11/25] at $6 \mathrm{mg} ; 46.7 \%$ [7/15] at $8 \mathrm{mg} ; 100 \%$ [2/2] at $7 \mathrm{mg}$; and $75 \%$ [3/4] at $10 \mathrm{mg}$ PER). (B) There was no association between the daily dose and adverse events rate. Twenty-three patients of the 34 in the adverse event group experienced an adverse event at only 1 to $4 \mathrm{mg}$, whereas 11 patients experienced adverse events during the increasing of the PER dose up to 5 to $10 \mathrm{mg}$ (seven adverse events at 5 to $7 \mathrm{mg}$; four adverse events at dose of $\geq 8 \mathrm{mg}$ ).

third AED were responders (three achieved seizure freedom and two achieved $\geq 50 \%$ seizure reduction). When PER was added as the fourth, fifth, or sixth AED, the response rate was $36.7 \%$ (11/30), 41.8\% (18/43), and 21\% (4/19), respectively.

There were eight patients who achieved seizure freedom. They had various etiologies-structural $(n=3)$, unknown $(n=4)$, and Gaucher disease $(n=1)$ - and seizure types_focal aware

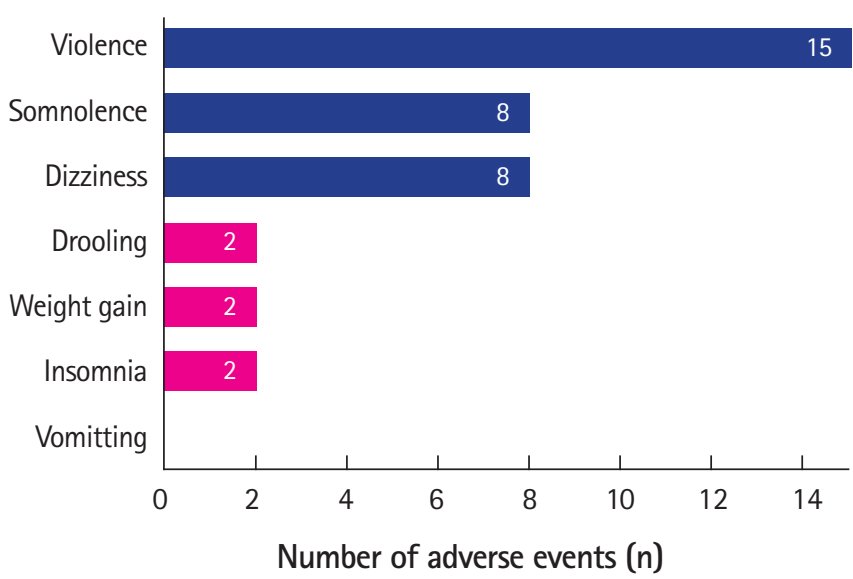

Fig. 3. Number of adverse events reported by patients after addup of perampanel (PER). Violence $(n=15)$ was the most common adverse event, followed by dizziness $(n=8)$ and somnolence $(n=8)$. Non-neuropsychiatric adverse events included drooling $(n=2)$, weight gain $(n=2)$, and vomiting $(n=2)$. Patients who experienced seizure aggravation after the addition of PER were excluded.

non-motor seizure $(\mathrm{n}=1)$, focal impaired awareness motor seizure $(n=4)$, and generalized motor seizure $(n=3)$. Four of them had undergone a prior epilepsy surgery or vagus nerve stimulation due to uncontrolled seizures but had no significant improvement in the seizure frequency. The mean maintenance dose was $4.25 \mathrm{mg} /$ day $(\mathrm{n}=3,2 \mathrm{mg} ; \mathrm{n}=3,4 \mathrm{mg}$; and $\mathrm{n}=2,8 \mathrm{mg})$. Three of these patients maintained seizure freedom at a PER dose of $2 \mathrm{mg}$.

\section{Tolerability}

Thirty-four patients (31.2\%) reported any adverse events: violence (15/108), somnolence $(8 / 108)$, dizziness $(8 / 108)$, drooling $(2 / 108)$, weight gain $(2 / 108)$, insomnia $(2 / 108)$, and vomiting (1/108) (Fig. 3).

The mean daily dose of PER in patients who experienced adverse effects was $4 \mathrm{mg} /$ day (1 to $10 \mathrm{mg}$ ). Twenty-three patients (23/59, $39 \%$ ) experienced adverse events at a lower dose of 1 to $4 \mathrm{mg}$ while seven patients $(7 / 30,23 \%)$ showed adverse events at 5 to $7 \mathrm{mg}$ and four patients (4/19,21\%) at the dose $\geq 8 \mathrm{mg}$ (Fig. 2B).

There was no significant difference in the sex, age at add-on of PER, and the number of concomitant AEDs between the adverse event group present and adverse event absent group (Table 3). Patients taking EIAEDs had a similar adverse event rate to the overall adverse event rate (CBZ 10/33, 33\%; OXC 6/15, 40\%; PHT $1 / 2,50 \%)$.

The retention rate was $68.0 \%$ in the first year and $59.5 \%$ in the second year of the study (Fig. 4). PER was discontinued in 34 patients because of seizure aggravation $(12 / 34)$ or occurrence of neuropsychiatric adverse events (dizziness, violence, somnolence 
Table 3. Comparison of the clinical factors between adverse event present and adverse event absent group

\begin{tabular}{lccc}
\hline Variable & Adverse event present $(n=34,31.4 \%)$ & Adverse event absent $(n=74,59.6 \%)$ & $P$ value \\
\hline Male sex & $17(50)$ & $47(63.5)$ & 0.18 \\
Age at the start of PER (yr) & $21.9 \pm 5.5$ & $19.4 \pm 4.6$ & 0.16 \\
No. of concomitant AEDs & $3.7 \pm 1.1$ & $3.9 \pm 1.0$ & 0.50 \\
Any EIAEDs & $15(44.1)$ & $33(44.6)$ & 0.99 \\
$\quad$ Oxcarbazepine & $10(29.4)$ & $23(31)$ & 0.90 \\
Carbamazepine & $6(17.6)$ & $8(10.8)$ & 0.43 \\
$\quad$ Phenytoin & $1(2.9)$ & $1(1.4)$ & 0.46 \\
Maintenance dose of PER (mg/day) & $4 \pm 2.3$ & $5.1 \pm 2.2$ & 0.02 \\
\hline
\end{tabular}

Values are presented as number (\%) or mean \pm standard deviation.

$P E R$, perampanel; $A E D$, antiepileptic drug; EIAED, enzyme-inducing antiepileptic drug.

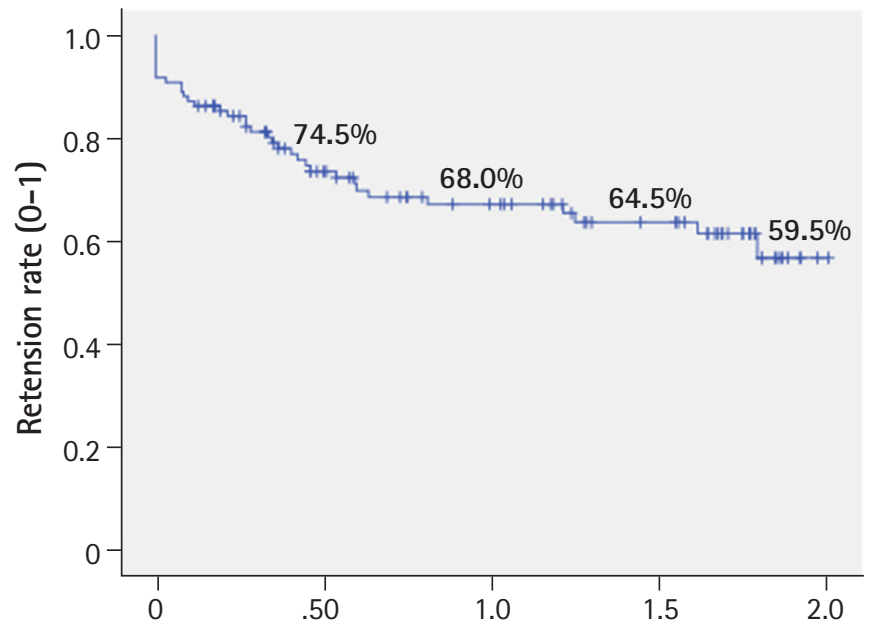

Time to withdrawal of perampanel (yr)

Fig. 4. Kaplan-Meier survival curve of perampanel retention times in patients with refractory epilepsy. The retention rate calculated by the Kaplan-Meier analysis was 68.0\% in the first year and $59.5 \%$ in the second year of the study. Due to seizure aggravation $(n=12)$ or psychiatric adverse events $(n=18)$, perampanel was discontinued in 34 patients.

or insomnia, 14/34). Among them, four patients showed seizure aggravation and neuropsychiatric adverse events at the same time. Seven patients who showed no improvement in seizure frequency stopped the PER and one patient who achieved seizure freedom stopped the PER maintain the seizure freedom status after discontinuation of PER.

Among 34 patients who experienced any adverse events, 13 patients stopped the PER immediately and nine patients tried to reduce daily PER dose. Despite PER dose reduction, six patients quitted the PER eventually. After withdrawal of the drug, the neuropsychiatric symptoms spontaneously resolved within weeks in all patients.

\section{Discussion}

This single-center, retrospective study supports the efficacy and tolerability of PER when used as an adjuvant treatment in patients with refractory epilepsy. There have been many studies on the efficacy and safety of PER, from randomized placebo-controlled trials to postmarketing observational studies [18-22,24-28]. Singh et al. [23] reported a $50 \%$ response rate ( $\geq 50 \%$ seizure reduction) in children and adults with various epilepsy syndromes with a mean daily dose of PER of $6.5 \pm 3.1 \mathrm{mg}$ (mean, 6). In an open-label extension study, Montouris et al. [27] increased the dose of PER to $12 \mathrm{mg} /$ day or up to the maximally tolerated individual dose. They reported a $55 \%$ response rate ( $\geq 50 \%$ seizure reduction) with a mean daily dose of $10.6 \pm 2.3 \mathrm{mg} /$ day [27]. The response rate ( $\geq 50 \%$ seizure reduction) in our study was slightly lower than those in the previous studies, which could be explained by the relatively lower mean daily dose of $4.8 \mathrm{mg} /$ day than those in the other study groups. Several recent studies supported the positive association between the dose and efficacy of PER [28,29]. In fact, the mean daily dose in the responder group patients who achieved $\geq 50 \%$ seizure reduction in this study was slightly higher than that in the non-responder group (5.3 vs. $4.4, P=0.04$ ).

Sixty patients among 108 patients maintain the daily PER dose $\leq 4 \mathrm{mg}$ and nineteen of them $(37 \%, 19 / 60)$ were responders in this study. Comparing to previous reports, more patients were treated with lower dose of 1 to $4 \mathrm{mg}$. De Liso et al. [18] reported that 12 patients are treated with 1 to $4 \mathrm{mg}$ among 62 patients who enrolled in multicenter observational study. In a recent retrospective study in Korea, Youn et al. [30] reported only seven patients maintain the daily PER dose of 1 to $4 \mathrm{mg}$ and showed $\geq 50 \%$ seizure reduction among 81 enrolled patients, showing that our results were not explained by difference in ethnic groups. The patients in this study had already used more AEDs (mean, 3.8; median, 4; maximum, 7; minimum, 2; interquartile range, 3 to 4 ) than 
other groups (De Liso et al. [18]: mean, 2.48; Youn et al. [30]: median, 3; maximum, 6; minimum, 1; interquartile range, 3 to 4 ) and it suggests the high intractability of the patients enrolled in this study. Despite of the intractability of our patient group, low dose of PER was effective in many of them. Recently, some authors suggested that the response rate do not appear to clearly correlate with PER daily dose and some patients can show response at low doses $[31,32]$. Our findings also support these opinions.

The duration of PER treatment was much longer in the responder group than non-responder group (13.5 months vs. 8.7 months, $P=0.03$ ). This difference could be explained by that there were much more patients who decided PER discontinuation in non-responder group ( 30 vs. $4, P=0.00$ ). There was no statistical difference in any other clinical factors between the responders and non-responders, including sex, age at seizure onset, duration of epilepsy, number of concomitant AEDs, concomitant EIAEDs and adverse events (\%).

In fact, the patients who were started on PER $(n=10)$ as the third AED showed a better response rate (50\%) than that in the other patients. A previous study also reported a better response rate in the patients in whom PER was added early (after $\leq 2$ prior AEDs; $72 \%$ were seizure-free) than that in patients in whom PER was added later ( $\geq 3$ prior AEDs; $52 \%$ were seizure-free) [33].

The overall adverse event rate was $31.5 \%$ (34/108), which is much lower than that reported in previous studies and can also be explained with the lower mean daily dose. Nevertheless, some patients showed psychiatric adverse events at a dose of only $2 \mathrm{mg}$ and eventually stopped taking the drug. The neuropsychiatric symptoms comprised $87 \%$ of all adverse events. The occurrence of psychiatric and neurologic symptoms after PER add-on was the main reason for drug withdrawal or dose reduction [22,23,30,34]. However, almost every patient who experienced psychiatric adverse events showed improvement in the symptoms after withdrawal of the drug or dose reduction. The clinical factors associated with the adverse events after addition of PER are not fully understood $[30,34]$. There were no contributing factors for adverse events, including sex, age, and number of concomitant AEDs and EIAEDs when comparing the adverse event present group with adverse event absent group.

PER is known to be extensively metabolized by the hepatic CYP3A4. Concomitant drugs that modulate CYP3A4 activity can reduce the half-life of PER by $50 \%$ to $70 \%$, resulting in lower PER serum concentrations [13,29,35]. However, EIAEDs had no significant effects on the efficacy and adverse event rate in this study. The interpersonal difference in the enzyme activity according to inherited genetics and use of other concomitant drugs can be considered. Further studies monitoring the serum concentration and CYP3A4 genetics could help find the optimal dose titration of PER.

There are some limitations of this study, including the retrospective design, the lack of seizure frequency data according to seizure types, and variable dose titration schedules. However, this study showed that low-dose PER is effective in patients with childhood-onset intractable epilepsy with good tolerability. Further, well-designed prospective study monitoring the serum concentration of PER can help determine the proper dose of PER in children and young adults with intractable epilepsy.

In conclusion, we demonstrated that PER is reasonably effective and tolerable in patients with refractory childhood-onset epilepsy. Tolerable low dose PER can be another choice for patients with intractable epilepsy.

\section{Conflicts of interest}

No potential conflicts of interest relevant to this article was reported.

\section{ORCID}

Hyeonmin Park, https://orcid.org/0000-0002-3606-4466

Tae-Sung Ko, https: / /orcid.org/0000-0002-8213-8964

\section{References}

1. Aaberg KM, Gunnes N, Bakken IJ, Lund Soraas C, Berntsen A, Magnus P, et al. Incidence and prevalence of childhood epilepsy: a nationwide cohort study. Pediatrics 2017;139:e20163908.

2. Lin KL, Lin JJ, Chou ML, Hung PC, Hsieh MY, Chou IJ, et al. Efficacy and tolerability of perampanel in children and adolescents with pharmacoresistant epilepsy: the first real-world evaluation in Asian pediatric neurology clinics. Epilepsy Behav 2018;85:188-94.

3. Franco V, Crema F, Iudice A, Zaccara G, Grillo E. Novel treatment options for epilepsy: focus on perampanel. Pharmacol Res 2013;70:35-40.

4. Plosker GL. Perampanel: as adjunctive therapy in patients with partial-onset seizures. CNS Drugs 2012;26:1085-96.

5. Rogawski MA. Revisiting AMPA receptors as an antiepileptic drug target. Epilepsy Curr 2011;11:56-63.

6. Graebenitz S, Kedo O, Speckmann EJ, Gorji A, Panneck H, Hans V, et al. Interictal-like network activity and receptor expression in the epileptic human lateral amygdala. Brain 2011; 134(Pt 10):2929-47.

7. Kitaura H, Sonoda M, Teramoto S, Shirozu H, Shimizu H, Kimura T, et al. $\mathrm{Ca}(2+)$-permeable AMPA receptors associated 
with epileptogenesis of hypothalamic hamartoma. Epilepsia 2017;58:e59-63.

8. Meldrum BS. The role of glutamate in epilepsy and other CNS disorders. Neurology 1994;44(11 Suppl 8):S14-23.

9. Rogawski MA. AMPA receptors as a molecular target in epilepsy therapy. Acta Neurol Scand Suppl 2013;197:9-18.

10. Seifert G, Huttmann K, Schramm J, Steinhauser C. Enhanced relative expression of glutamate receptor 1 flip AMPA receptor subunits in hippocampal astrocytes of epilepsy patients with Ammon's horn sclerosis. J Neurosci 2004;24:1996-2003.

11. Vollmar W, Gloger J, Berger E, Kortenbruck G, Kohling R, Speckmann EJ, et al. RNA editing (R/G site) and flip-flop splicing of the AMPA receptor subunit GluR2 in nervous tissue of epilepsy patients. Neurobiol Dis 2004;15:371-9.

12. Zilles K, Qu MS, Kohling R, Speckmann EJ. Ionotropic glutamate and GABA receptors in human epileptic neocortical tissue: quantitative in vitro receptor autoradiography. Neuroscience 1999;94:1051-61.

13. Ishikawa N, Tateishi Y, Tani H, Kobayashi Y, Kobayashi M. Clinical profiles associated with serum perampanel concentrations in children with refractory epilepsy. Epilepsy Behav 2019;94:82-6.

14. Glauser T, Laurenza A, Yang H, Williams B, Ma T, Fain R. Efficacy and tolerability of adjunct perampanel based on number of antiepileptic drugs at baseline and baseline predictors of efficacy: a phase III post-hoc analysis. Epilepsy Res 2016;119:34-40.

15. Sheridan PH. Summary review [Internet]. Silver Spring: FDA; 2017 [cited 2019 Sep 24]. Available from: https://www.fda. gov/media/124207/download.

16. Eisai. FDA approves Eisai's FYCOMPA ${ }^{\circledR}$ (perampanel) for use as monotherapy for the treatment of partial-onset seizures [Internet]. Woodcliff Lake: Eisai Inc.; 2017 [cited 2019 Sep 24]. Available from: http://eisai.mediaroom.com/2017-07-26FDA-Approves-Eisais-FYCOMPA-R-perampanel-for-Use-asMonotherapy-for-the-Treatment-of-Partial-Onset-Seizures.

17. Eisai. Eisai announces FDA approval Of FYCOMPA ${ }^{\circledast}$ in pediatric patients as young as 4 years old for the treatment of partial-onset seizures [Internet]. Woodcliff Lake: Eisai Inc.; 2018 [cited 2019 Sep 24]. Available from: http://eisai.mediaroom. com/2018-09-28-Eisai-Announces-FDA-Approval-Of-FYCOMPA-R-in-Pediatric-Patients-As-Young-As-4-Years-OldFor-The-Treatment-Of-Partial-Onset-Seizures.

18. De Liso P, Vigevano F, Specchio N, De Palma L, Bonanni P, Osanni E, et al. Effectiveness and tolerability of perampanel in children and adolescents with refractory epilepsies: an Italian observational multicenter study. Epilepsy Res 2016;127:93100.

19. French JA, Krauss GL, Biton V, Squillacote D, Yang H, Laurenza
A, et al. Adjunctive perampanel for refractory partial-onset seizures: randomized phase III study 304. Neurology 2012; 79:589-96.

20. French JA, Krauss GL, Steinhoff BJ, Squillacote D, Yang H, Kumar D, et al. Evaluation of adjunctive perampanel in patients with refractory partial-onset seizures: results of randomized global phase III study 305. Epilepsia 2013;54:117-25.

21. Krauss GL, Serratosa JM, Villanueva V, Endziniene M, Hong Z, French J, et al. Randomized phase III study 306: adjunctive perampanel for refractory partial-onset seizures. Neurology 2012;78:1408-15.

22. Shah E, Reuber M, Goulding P, Flynn C, Delanty N, Kemp S. Clinical experience with adjunctive perampanel in adult patients with uncontrolled epilepsy: a UK and Ireland multicentre study. Seizure 2016;34:1-5.

23. Singh K, Shah YD, Luciano D, Friedman D, Devinsky O, Kothare SV. Safety and efficacy of perampanel in children and adults with various epilepsy syndromes: a single-center postmarketing study. Epilepsy Behav 2016;61:41-5.

24. Steinhoff BJ, Bacher M, Bast T, Kornmeier R, Kurth C, Scholly J, et al. First clinical experiences with perampanel: the Kork experience in 74 patients. Epilepsia 2014;55 Suppl 1:16-8.

25. Steinhoff BJ, Hamer H, Trinka E, Schulze-Bonhage A, Bien C, Mayer T, et al. A multicenter survey of clinical experiences with perampanel in real life in Germany and Austria. Epilepsy Res 2014;108:986-8.

26. Usui N, Akamatsu N, Nakasato N, Ohnishi A, Kaneko S, Hiramatsu $\mathrm{H}$, et al. Long-term tolerability, safety and efficacy of adjunctive perampanel in the open-label, dose-ascending Study 231 and extension Study 233 in Japanese patients with epilepsy. Seizure 2018;62:26-32.

27. Montouris G, Yang H, Williams B, Zhou S, Laurenza A, Fain R. Efficacy and safety of perampanel in patients with drug-resistant partial seizures after conversion from double-blind placebo to open-label perampanel. Epilepsy Res 2015;114:131-40.

28. Nishida T, Lee SK, Inoue Y, Saeki K, Ishikawa K, Kaneko S. Adjunctive perampanel in partial-onset seizures: Asia-Pacific, randomized phase III study. Acta Neurol Scand 2018;137:392-9.

29. Gidal BE, Ferry J, Majid O, Hussein Z. Concentration-effect relationships with perampanel in patients with pharmacoresistant partial-onset seizures. Epilepsia 2013;54:1490-7.

30. Youn SE, Kim SH, Ko A, Lee SH, Lee YM, Kang HC, et al. Adverse events during perampanel adjunctive therapy in intractable epilepsy. J Clin Neurol 2018;14:296-302.

31. Morano A, Fattouch J, Albini M, Casciato S, Fanella M, Basili LM, et al. Perampanel as adjunctive therapy in highly refractory epilepsies: real-world data from an Italian tertiary care epilepsy 


\section{centre. J Neurol Sci 2018;390:67-74.}

32. Stavropoulos I, Louden W, Queally C, Adcock J, Tristram M, Neale M, et al. Perampanel for the treatment of epilepsy: longitudinal actuarial analysis and dose responses based on monthly outcomes. Seizure 2019;69:125-32.

33. Villanueva V, Montoya J, Castillo A, Mauri-Llerda JA, Giner P, Lopez-Gonzalez FJ, et al. Perampanel in routine clinical use in idiopathic generalized epilepsy: the 12-month GENERAL study. Epilepsia 2018;59:1740-52.

34. Zaccara G, Giovannelli F, Cincotta M, Verrotti A, Grillo E. The adverse event profile of perampanel: meta-analysis of randomized controlled trials. Eur J Neurol 2013;20:1204-11.

35. Faulkner MA. Spotlight on perampanel in the management of seizures: design, development and an update on place in therapy. Drug Des Devel Ther 2017;11:2921-30. 